investigation regarding etiology.

It is well known that in general the brain abscess originates from chronic otiti in many cases. However Arzeni pointed out that in the newborn under a year 0 age chronic otitis does not exist for the reason of the anatomical structure.

We could not find any heart disease in our two cases, though it is also statec by some authors that the abnormal cerebral circulation due to congenital heart dis. ease promote the incidence of brain abscess. The cause and symptom of brair abscess are difficult to recognize, hence the diagnosis is difficult to make pre-opera. tively except in the typical case.

It is not rare that the brain abscess can be differenciated from hydrocephalus and brain tumor only through puncture and or craniotomy.

Dandy emphasize aspiration of pus by puncture to be sufficient for the treatment of brain abscess, whereas Vincent insists the necessity of total resection of the abscess after formation of capsule is complete. Since tentorial herniation due to the increase of intracranial pressure was demonstrated in one of our two cases, we believe that in the newborn aspiration of the abscess cavity should be performed as soon as the diagnosis is established.

\title{
33. Cerebral Abscess associated with Congenital Heart Disease
}

\author{
Toshio Beppu, Yasuharu AraI, Hidemaro Kuramitsu \\ and Eiho YAMAGUCHI \\ Department of Surgery Tokyo Women's College
}

During 12 yrs. from 1956, 18 cases of cerebral abscess associated with cyanotic congenital heart disease ( 3 yrs. -26 yrs. old) were confirmed by surgical procedure and autopsy. (approximately $1 \%$ frequency), 14 cases of them were Tetralogy of Fallot. This disease progresses rapidly and becomes critically ill, and expires before diagnosis could be made in 8 of the cases in the past. But for these 4 years, 10 cases of the above 18 cases were diagnosed by angiography, cerebro-spinal findings, blood counts, EEG and eye-ground examination. 9 cases were operated and 1 case with multiple abscess of the right hemisphere could not be operated.

18 cases $\left\{\begin{array}{l}8 \text { cases } \ldots \text { died before diagnosis } \\ 10 \text { cases }\left\{\begin{array}{l}9 \text { cases operated } \\ 1 \text { case died after diagnosis }\end{array}\right.\end{array}\right.$

The operation method of 9 cases are as follows 
9 cases $\left\{\begin{array}{l}4 \text { cases aspiration and repeated taps }\left\{\begin{array}{l}3 \text { cases alive } \\ 1 \text { case died } \\ 1 \text { case drainage }\end{array}\right\} \text { died }\end{array}\right.$

The cause of dead cases (operated)

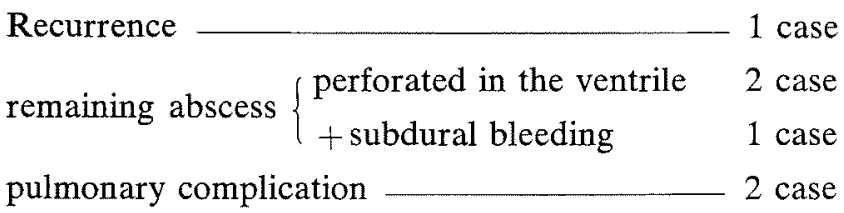

The post-operative care become difficult by the facts of the cyanotic heart disease showed as follows

1. polycythemia $\longrightarrow \stackrel{\text { thrombus }}{\text { formation }} \longrightarrow \stackrel{\text { low molecular }}{\text { Dextran transsion }}$
2. hypoxia collateral $\longrightarrow$ hemorrhagic $\longrightarrow$ fresh blood transfusion vessels fibrinolysis $\longrightarrow$ tendency $\longrightarrow$ autiplasmin etc.

3. destruction of alveolar wall $\longrightarrow$ atelectasis $\longrightarrow$ controlled hypoplasia of pulmonary artery $\longrightarrow$ atelectasis $\longrightarrow$ respiration

Also emergency operation during the excerbated cases, by means of aspiration using repeated taps may save the patient. The occurrence of brain abscess in left aortic arch has predominance in right hemisphere and right aortic arch in left hemisphere.

\title{
34. Experimental Petit Mal in the Macaque Monkey
}

\author{
A. Earl WALKER
}

Dept. of Neurological Surgery, Johns Hopkins Hospital

\section{Clinical Results of Forel-H-tomy for the Treatment of Epilepsy}

Jiro Mukawa, Dennosuke JinnaI, Heitaro Mogami, Masahiko Ioku, Kiyoo Kamikawa, Takuya Ikeda, Yoshikazu Iwata and Kiyofumi KoBAYASHI

Department of Neurosurgery, Osaka University School of Medicine

$$
-69-
$$

